\title{
BMJ Open Paradox of self-care gender differences among Italian patients with chronic heart failure: findings from a real-world cross-sectional study
}

\author{
Federica Dellafiore, ${ }^{1}$ Cristina Arrigoni, ${ }^{2}$ Francesco Pittella, ${ }^{1}$ Gianluca Conte, ${ }^{1}$ \\ Arianna Magon, ${ }^{1}$ Rosario Caruso ${ }^{1}$
}

To cite: Dellafiore F, Arrigoni C, Pittella F, et al. Paradox of self-care gender differences among Italian patients with chronic heart failure: findings from a real-world crosssectional study. BMJ Open 2018;8:e21966. doi:10.1136/ bmjopen-2018-021966

- Prepublication history for this paper is available online To view these files, please visit the journal online (http://dx.doi. org/10.1136/bmjopen-2018021966).

Received 30 January 2018 Revised 15 May 2018 Accepted 31 August 2018

\section{A) Check for updates}

\section{(c) Author(s) (or their} employer(s)) 2018. Re-use permitted under CC BY-NC. No commercial re-use. See rights and permissions. Published by BMJ.

${ }^{1}$ Health Professions Research and Development Unit, IRCCS Policlinico San Donato, San Donato Milanese, Italy ${ }^{2}$ Department of Public Health, Experimental and Forensic Medicine, Unit of Hygiene, University of Pavia, Pavia, Italy

Correspondence to Dr Rosario Caruso; rosario.caruso@unimi.it

\section{ABSTRACT}

Aim The aim of this study was to critically analyse and describe gender differences related to self-care among patients with chronic heart failure (HF).

Methods and results A monocentric real-world cohort of 346 patients with chronic HF in follow-up was used for this cross-sectional study. We report data related to the cohort's demographic and clinical characteristics. Selfcare was assessed using the Self-Care of Heart Failure Index before patients' discharge. After bivariate analysis, logistical regression models were used to describe the relationship between gender, self-care behaviours and self-care confidence. While men were found to have more than quadruple the risk of poor self-care than women (OR 4.596; $95 \% \mathrm{Cl} 1.075$ to 19.650 ), men were also found to be approximately $60 \%$ more likely to have adequate self-care confidence than women (OR 0.412; $95 \% \mathrm{Cl}$ 0.104 to 0.962$)$. Considering that self-care confidence is described as a positive predictor of behaviours, our results suggest a paradox. It is possible that the patientcaregiver relationship mediates the effect of confidence on behaviours. Overall, adequate levels of self-care behaviours are a current issue, ranging $7.6 \%-18.0 \%$. Conclusion This study sets the stage for future research where elements of the patient-caregiver relationship ought to be considered to inform the planning of appropriate educational interventions. We recommend routinely measuring patients' self-care behaviours to guide their follow-up and as a basis for any changes in their daily life behaviours.

\section{INTRODUCTION}

The rate of heart failure (HF) is steadily increasing worldwide, becoming an important public health issue. ${ }^{12} \mathrm{HF}$ affects more than 15 million people in Europe and its prevalence is rising, with the global prevalence of HF expected to reach $25 \%$ by $2030 .^{3}$ Currently, the prevalence of HF among European and American adults ranges 0.4\%$2.3 \% .^{4}$ The most common causes of HF are related to issues with the valves, myocardium, pericardium, endocardium or heart rhythm abnormalities. ${ }^{5}$ These, along with multiple
Strengths and limitations of this study

- This is the first study in the last 5 years aimed at exploring gender differences in self-care among patients with chronic heart failure.

- Gender differences are an important determinant of self-care, with gender-based self-care behaviours being culturally determined. As such, gender-specific educational interventions may be effective in influencing these gender-based self-care behaviours.

- Italian men have more than quadruple the risk of poor self-care than women, while also being approximately $60 \%$ more likely to have adequate self-care confidence than women. Paradoxically, confidence is usually a positive predictor of self-care maintenance.

- Understanding gender differences in patients' responses to pathology is a necessary precursor to reducing inequalities in healthcare delivery and allows for the development of targeted evidence-based educational interventions.

- Our findings are not generalisable outside of Italy; as such, more cross-cultural investigations are needed.

comorbidities, often result in chronic HF. In such cases, patients are asked to abide by list of evidence-based clinical recommendations aimed at optimising their health, monitoring their symptoms and to engage appropriate decision-making to manage their signs and symptoms. ${ }^{67}$ Recent studies show how patients with HF outcomes are closely linked to their self-care, which is their ability to maintain their health through health promoting practices and illness management. ${ }^{7-10}$

Academic interest in self-care has grown following the development of middle range theories of reference, ${ }^{7}$ with these theories facilitating efforts to investigate the relationship between self-care and clinical outcomes in patients with HF. A high standard of self-care in patients with $\mathrm{HF}$ is associated with improved quality of life, ${ }^{11}{ }^{12}$ reduced 
rehospitalisations, ${ }^{13}$ reduced mortality ${ }^{14}$ and lower healthcare costs. ${ }^{14}$ Evidence shows that patients with HF who participate in educational interventions aimed at improving self-care exhibit improvements in their emotional quality of life as well as overall health status after just 3 months. ${ }^{1112}$ Other studies indicate that poor self-care is an independent risk factor for adverse clinical outcomes in patients with $\mathrm{HF}$ and rehospitalisations. ${ }^{13}$ These adverse clinical outcomes also include the death of patients with HF with poor self-care. ${ }^{14}$ One common characteristic of patients with poor self-care is a reduction in their use of HF-related medications over time (ie, poor adherence). This implies a greater likelihood of rehospitalisation and an increase in healthcare costs; conversely, HF management in patients with adequate levels of selfcare is far less taxing in terms of healthcare economic resources. ${ }^{14}$

In this scenario, gender differences are an important peculiarity of self-care. These gender differences, however, may be culturally determined. With this being the case, gender-specific educational interventions may be beneficial in addressing some of these gender-specific characteristics. Understanding these gender differences can inform interventions aimed at closing the gender gap and reducing inequalities in healthcare delivery. ${ }^{15}$ Current research suggests a range of gender differences in chronic HF; however, the findings of these studies are often contradictory. For example, while some studies indicate that men have better self-care behaviours than women, ${ }^{16}$ other studies demonstrate poor self-care behaviours among men. ${ }^{17}$ That said, there is still much about gender differences in self-care that we do not know; for example, whether it is possible to estimate the likelihood of inadequate/adequate self-care in relation to gender in real-world cohorts. Understanding the peculiarities of how gender difference influence patients' selfcare behaviours is important for planning appropriate treatment and education. ${ }^{518}$

Currently, the evidence base for understanding gender differences in patients with chronic HF is weak. What evidence exists in this regard is largely inferred by way of the secondary results of studies aimed to describing selfcare. For this reason, the aim of this study was to critically analyse and describe gender differences related to self-care among patients with chronic HF. The results of this study make a significant contribution to our understanding of these gender and behavioural differences, and can provide a wealth of epidemiological information useful for planning future tailored interventions.

\section{METHODS}

\section{Design and participants}

This is an observational, single-centre design study using real-world convenience sampling. The sample includes all patients seen at a clinic in a research hospital located in Policlinico San Donato, Northern Italy. To be enrolled, all patients had to have a diagnosis of stable chronic
HF and they had to have a recent cardiac assessment (maximum 1 week before intake). Therefore, using realworld sampling, all patients with chronic HF related to a cardiac causes and assessed by their cardiologist within 1 week prior to our study were eligible for participation. ${ }^{19}$ Cardiological clinical assessment of the enrolled patients was performed in accordance with current guidelines. ${ }^{5}$ All data were collected using a cross-sectional approach, between January and September 2017. The only exclusion criteria for this study were: (1) inability to read and speak Italian, (2) diagnosis of psychiatric or cognitive problems and (3) patients aged under 18. Although this study used real-world sampling, these exclusion criteria were necessary to ensure that participants could complete all self-report instruments.

\section{Measures}

We recorded data on participants' demographic and clinical characteristics. Self-care behaviours were assessed before the patients discharge using the Self-Care of Heart Failure Index (SCHFI V.6.2).

\section{Demographic and clinical characteristics}

We report on the following cohort demographic and clinical characteristics: age, gender, nationality, body mass index (BMI), New York Heart Association (NYHA) functional classification, ejection fraction $(\mathrm{EF})$, secondary cardiac diagnosis associated to $\mathrm{HF}$ and drug treatment. Given the real-world approach used in this study, we used the Cumulative Illness Rating Scale (CIRS) to control for multiple forms of morbidity. ${ }^{20}$ BMI was categorised in accordance to the Centers for Disease Control and Prevention recommendations (ie, underweight, healthy weight, overweight, obese). ${ }^{21}$ Participants' NYHA classification and HF were reported in line with current guidelines. ${ }^{5}$ CIRS was used to evaluate multimorbidity, considering the gravity of comorbid medical conditions in 14 main domains. Each domain represents a physiopathological system, with scores ranging $0-4$ for the assessment; $0=$ no problem, $4=$ extremely severe problem. The CIRS algorithm and subsequent indications result in an overall score for comorbidities that ranges $0-4 .^{20}$ For this study, the authors used an online calculator as provided by the Italian Society of Haematology.

\section{Self-Care of Heart Failure Index (V.6.2)}

SCHFI is a 22-item self-report instrument used to measure self-care in patients with HF. The SCHFI measures selfcare within a well-defined framework, having been developed using a situation-specific theory of reference. ${ }^{22}$ The 22 items of the instrument are grouped according to three scales used to measure both self-care behaviours (ie, self-care maintenance and self-care management) and the self-efficacy in performing said behaviours (ie, self-care confidence). According to Riegel et al, patients' self-care confidence is theorised to have an effect on patients' self-care behaviours and is not an element of self-care per se. ${ }^{23}$ The two behavioural measures are 
self-care maintenance and self-care management. Selfcare maintenance describes patients' level of engagement in behaviours aimed at maintaining their stability, monitoring their signs and symptoms and adhering to their treatment. Conversely, self-care management describes patients' ability to recognise their symptoms and to take appropriate treatment-orientated actions when needed (eg, consult a healthcare provider or reduce fluid intake). Each scale in the SCHFI uses a 4-point self-report response format, ranging $1=$ never or rarely to $4=$ always or daily. To compute the score for each scale, raw scores must be transformed into standardised scores in the order of 0-100, following the procedure described in SCHFI validation studies. ${ }^{22}{ }^{24}$ Adequate self-care behaviours and self-care confidence are indicated by scores higher than $70 .^{22} 24$

\section{Data analysis}

All data were checked to assess for possible missing data, erroneous entries or outliers against a frequency distribution. Missing data were managed using a pairwise approach. A study of skewness was used to provide a preliminary assessment of the distribution of variables, which was followed by a Kolmogorov-Smirnov test. Continuous variables were expressed as mean and SD for normally distributed data, while non-normally distributed variables were expressed as median and IQR. Categorical variables have been described by numbers and percentages. All data were preliminary tested via univariate analysis, where categorical variables were tested by contingency table analysis (ie, $\chi^{2}$ test or Fisher's exact test, when appropriate), and continuous variable were tested by Mann-Whitney U test or Student's t-test (when appropriate). A bivariate analysis was performed to assess the relationship between gender and other variables using point-polyserial correlation (Rpp). Logistic regression (LR) models were used in the multivariable analysis to describe gender differences related to self-care maintenance, management and confidence. LR models were developed considering these univariate analysis interpretations and bivariate analysis, the theoretical rationale, precautions to avoid model overfit, ${ }^{25}$ conformity with linear gradient for the included continuous variables, control of possible collinearity among the independent variables, the study of statistical significance using both Wald's $\chi^{2}$ and likelihood ratio test, an assessment of goodness-of-fit measures through the Hosmer-Lemeshow test, and the analysis of pseudo- $\mathrm{R}^{2}$ (ie, Cox and Snell; Nagelkerke and McFadden)..$^{25}$ All predictor variables selected from the univariate analysis were entered simultaneously into the equation models to control for each other. Statistics were performed using SPSS (V.22, IBM) and R Statistical Package (R Foundation for Statistical Computing). All tests were two tailed, setting a significance level of $5 \%$.

\section{Patient and public involvement}

We carefully considered patients' priorities, experience and preferences during the process of informed consent counselling. All patients are informed about the ways to

\begin{tabular}{|c|c|c|}
\hline Demography & & N (\%) \\
\hline \multirow[t]{3}{*}{ Mean (SD) } & Age (years) & $65.6(13.6)$ \\
\hline & Gender (male/female) & $61.1 \% / 38.9 \%$ \\
\hline & Nationality (Italian) & $100 \%$ \\
\hline \multicolumn{3}{|l|}{ Anthropometry } \\
\hline Mean (SD) & Body mass index $\left(\mathrm{kg} / \mathrm{m}^{2}\right)$ & $26.95(4.97)$ \\
\hline \multicolumn{3}{|c|}{ Clinical characteristics } \\
\hline & Class II & $256(74.0 \%)$ \\
\hline & Class III & $82(23.7 \%)$ \\
\hline & Class IV & $8(2.3 \%)$ \\
\hline & $\begin{array}{l}\text { reduced Ejection Fraction } \\
(<40 \%)\end{array}$ & $82(23.7 \%)$ \\
\hline & $\begin{array}{l}\text { Mid-range Ejection } \\
\text { Fraction }(40 \%-50 \%)\end{array}$ & $101(29.2 \%)$ \\
\hline & $\begin{array}{l}\text { Preserved ejection fraction } \\
(\geq 50 \%)\end{array}$ & $163(47.1 \%)$ \\
\hline & $\begin{array}{l}\text { Cumulative Illness Rating } \\
\text { Scale (CIRS) total score } 0\end{array}$ & $270(78.0 \%)$ \\
\hline & CIRS total score 1 & $50(14.5 \%)$ \\
\hline & CIRS total score 2 & $26(7.5 \%)$ \\
\hline \multicolumn{3}{|c|}{ Secondary cardiac diagnosis } \\
\hline & Myocardial Infarction & $225(65.0 \%)$ \\
\hline & Hypertension & $176(50.9 \%)$ \\
\hline & Atrial fibrillation & $111(30.1 \%)$ \\
\hline \multicolumn{3}{|l|}{ Drug treatment } \\
\hline & ACE inhibitors & $73(21.1 \%)$ \\
\hline & B-blockers & $87(25.1 \%)$ \\
\hline & Diuretics & $270(78.0 \%)$ \\
\hline & Cardiac glycosides & $160(46.2 \%)$ \\
\hline & Aspirin or salicylates & $222(64.2 \%)$ \\
\hline & Calcium channel blockers & $74(21.4 \%)$ \\
\hline \multicolumn{3}{|c|}{ 'Adequate' self-care (scores $\geq 70$ ) } \\
\hline & Maintenance & $66(18.0 \%)$ \\
\hline & Management & $28(7.6 \%)$ \\
\hline & Confidence & $131(35.7 \%)$ \\
\hline
\end{tabular}

contact the principal investigation in case they wish to receive more information on the study development and findings. Patients' active involvement was related to the sole period of data collection.

\section{RESULTS}

\section{Sample}

A sample of 346 patients with chronic HF was enrolled in this study. Participant characteristics are shown in table 1. The majority of participants were male $(\mathrm{n}=256 ; 74.0 \%)$, with an average age of 65.1 years $(\mathrm{SD}=13.6)$. The mean BMI was $26.95 \mathrm{~kg} / \mathrm{m}^{2}$ ( $\left.\mathrm{SD}=4.97\right)$. The majority of participants were satisfied criteria for NYHA class II $(n=199$, 
$57.5 \%)$, with a preserved EF $(\mathrm{n}=163 ; 47.1 \%)$. The most frequent secondary cardiac diagnosis associated with chronic HF was myocardial infarction $(\mathrm{n}=225 ; 65.0 \%)$, followed by hypertension $(\mathrm{n}=176 ; 50.9 \%)$ and atrial fibrillation $(\mathrm{n}=111 ; 30.1 \%)$. Only 66 participants reported adequate self-care maintenance (18.0\%), 28 participants had an adequate self-care management $(7.6 \%)$ and 131 participants had an adequate self-confidence $(35.7 \%)$.

\section{Gender differences}

Considering the bivariate analysis, gender (male $=1$; female $=2)$ was significantly related to CIRS $(\mathrm{Rpp}=0.157$; $\mathrm{p}=0.005)$ and self-care maintenance $(\mathrm{Rpp}=-0.112$; $\mathrm{p}=0.025$ ) (where $1=$ adequate self-care maintenance, 2=inadequate self-care maintenance), self-care management (Rpp=-0.101; $\mathrm{p}=0046) \quad$ (where $1=$ adequate selfcare management, 2=inadequate self-care management), self-care confidence $(\mathrm{Rpp}=+0.158 ; \mathrm{p}=0.011) \quad$ (where, $1=$ adequate self-care confidence, $2=$ =inadequate self-care confidence. Therefore, male participants reported less comorbidity, as well as lower self-care maintenance and management scores, but higher self-care confidence.

As shown in table 2, according to the first LR model, the likelihood of inadequate self-care maintenance is reduced by roughly $80 \%$ when patients have adequate levels of self-care confidence (OR 0.188; 95\% CI 0.042 to 0.843 ) and self-care management (OR $0.182 ; 95 \%$ CI 0.037 to 0.892 ), while males were found to be more than four times as likely as females to demonstrate inadequate self-care maintenance (OR 4.596; 95\% CI 1.075 to 19.650). The second LR model shows that the likelihood of inadequate self-care management decreases by approximately $83 \%$ when patients have adequate maintenance (OR $0.171 ; 95 \%$ CI 0.036 to 0.816 ). No relationship was found between gender and self-care management. The third LR model shows that the likelihood of inadequate self-care confidence decreases by roughly $80 \%$ when patients have adequate levels of self-care maintenance (OR 0.211; $95 \% \mathrm{CI} 0.051$ to 0.869 ), and that males approximately $60 \%$ more likely to possess adequate selfcare confidence than women (OR $0.412 ; 95 \%$ CI 0.104 to 0.962). Moreover, every point reduction in the CIRS total score is associated with a $70 \%$ increase in the likelihood of the patient possessing adequate levels of self-care confidence (OR 0.297; 95\% CI 0.102 to 0.865 ).

\section{DISCUSSION}

To the best of our knowledge, this was the first study in last 5 years to have explored the issues of gender differences in the self-care of patients with chronic HF. Understanding these gender differences is important for informing evidence-based educational interventions aimed at improving self-care behaviours within this patient population. Our results indicate that gender is strongly correlated with self-care behaviours. Our LR models allow for the investigation of gender differences using multivariable approaches, where self-care behaviours and self-care confidence are treated as dichotomous outcomes (ie, inadequate vs adequate). Specifically, gender is significantly associated with self-care maintenance and self-care confidence, where males are more than four times as likely to exhibit inadequate self-care maintenance than females. Males are also approximately $60 \%$ more likely to describe having adequate self-care confidence than females. These results present somewhat of a paradox, with current theories and evidence indicate that self-care confidence should positively predict self-care behaviours. ${ }^{7627}$ Nonetheless, this paradox is tangible in our results, considering the relationship between self-care confidence and adequate self-care behaviours (table 2). For example, we can see that men are significantly less likely than women to demonstrate adequate levels of self-care maintenance, despite being roughly $60 \%$ more likely than women to have adequate levels of self-care confidence.

In short, our understanding of gender differences in both Italian patients with chronic $\mathrm{H}$ and the wider chronic HF population may be missing some important elements. Future investigations are needed to better understand this paradox. Having a better understanding of these gender differences might allow for the development of tailored educational intervention, specific to the needs of each gender, prior to the patient's discharge. Patient education is an integral part of treatment and rehabilitation $^{5}$; therefore, understanding the nature of this paradox is important to ensure that the efficacy of educational interventions is not undermined by gaps in knowledge concerning educational best practice. To improve our understanding of this phenomenon, future investigations should take into account the potential role of comorbidities related to mental disorders by measuring depression and anxiety, ${ }^{28-30}$ and by the determining the potential influence of self-delusion with respect to self-care. ${ }^{31}$ Literature suggests that patients with even minor depression exhibit lower levels of self-care than patients with major depression, and women are more likely to present with anxiety; however, there is currently no evidence of gender differences in terms of the self-care-depression relationship. ${ }^{28}$ Moreover, the greater self-care confidence of males should predict greater self-care knowledge; however, there are no evidence that males have a deeper understanding of their chronic HF than females. This could imply that the greater self-care confidence seen in males is simply the product of a form of self-delusion. ${ }^{31}$ Moreover, the effect of this self-delusion might be enhanced when male patients are threatened by a perceived loss of autonomy and control, thus providing one possible explanation for the aforementioned paradox.

Notwithstanding, any evidence arising out of the study of gender differences needs to be contextualised to the patients' cultural norms. Consequently, the literature describes a broad range of conflicting results when the evidence of multisite international studies are compared. De facto, evidence coming fromUSA shows that men are more likely to undertake independent decisions about their self-care management, while women have higher 
Table 2 Models of logistic regression analysis

Maintenance

\begin{tabular}{|c|c|c|c|c|c|c|c|}
\hline \multirow[t]{6}{*}{ Predictors } & & Wald's $\chi^{2}$ & df & $P$ values & OR & $95 \% \mathrm{Cl}$ & \\
\hline & Constant & 2.356 & 1 & 0.125 & - & - & \\
\hline & $\begin{array}{l}\text { Confidence (adequate vs } \\
\text { inadequate) }\end{array}$ & 4.767 & 1 & 0.029 & 0.188 & 0.042 to 0.843 & \\
\hline & $\begin{array}{l}\text { Management (adequate vs } \\
\text { inadequate) }\end{array}$ & 4.413 & 1 & 0.036 & 0.182 & 0.037 to 0.892 & \\
\hline & CIRS & 2.314 & 1 & 0.128 & 2.909 & 0.735 to 11.512 & \\
\hline & Gender (male vs female) & 4.232 & 1 & 0.04 & 4.596 & 1.075 to 19.650 & \\
\hline \multirow[t]{3}{*}{ Model } & & $\chi^{2}$ & df & $P$ values & $\begin{array}{l}\text { Pseudo- }{ }^{2} \\
\text { (Cox and } \\
\text { Snell) }\end{array}$ & $\begin{array}{l}\text { Pseudo- } R^{2} \\
\text { (Nagelkerke) }\end{array}$ & $\begin{array}{l}\text { Pseudo- } R^{2} \\
\text { (McFadden) }\end{array}$ \\
\hline & Likehood ratio test & 18.69 & 9 & 0.028 & 0.241 & 0.351 & 0.238 \\
\hline & Hosmer-Lemeshow test & 4.185 & 6 & 0.665 & - & - & - \\
\hline \multicolumn{8}{|c|}{ Management } \\
\hline \multirow[t]{6}{*}{ Predictors } & & Wald's $\chi^{2}$ & df & $P$ values & OR & $95 \% \mathrm{Cl}$ & \\
\hline & Constant & 0.799 & 1 & 0.271 & - & - & \\
\hline & $\begin{array}{l}\text { Confidence (adequate vs } \\
\text { inadequate) }\end{array}$ & 1.992 & 1 & 0.158 & 0.318 & 0.065 to 1.561 & \\
\hline & $\begin{array}{l}\text { Maintenance (adequate vs } \\
\text { inadequate) }\end{array}$ & 4.902 & 1 & 0.027 & 0.171 & 0.036 to 0.816 & \\
\hline & CIRS & 0.265 & 1 & 0.607 & 0.729 & 0.219 to 2.429 & \\
\hline & Gender (male vs female) & 0.88 & 1 & 0.348 & 2.126 & 0.440 to 10.284 & \\
\hline \multirow[t]{3}{*}{ Model } & & $\chi^{2}$ & df & $P$ values & $\begin{array}{l}\text { Pseudo- }{ }^{2} \\
\text { (Cox and } \\
\text { Snell) }\end{array}$ & $\begin{array}{l}\text { Pseudo- } R^{2} \\
\text { (Nagelkerke) }\end{array}$ & $\begin{array}{l}\text { Pseudo- } R^{2} \\
\text { (McFadden) }\end{array}$ \\
\hline & Likehood ratio test & 16.3 & 9 & 0.049 & 0.218 & 0.336 & 0.241 \\
\hline & Hosmer-Lemeshow test & 3.404 & 6 & 0.696 & - & - & - \\
\hline \multicolumn{8}{|l|}{ Confidence } \\
\hline \multirow[t]{6}{*}{ Predictors } & & Wald's $\chi^{2}$ & df & $P$ values & OR & $95 \% \mathrm{Cl}$ & \\
\hline & Constant & 2.758 & 1 & 0.097 & - & - & \\
\hline & $\begin{array}{l}\text { Maintenance (adequate vs } \\
\text { inadequate) }\end{array}$ & 4.644 & 1 & 0.031 & 0.211 & 0.051 to 0.869 & \\
\hline & $\begin{array}{l}\text { Management (adequate vs } \\
\text { inadequate) }\end{array}$ & 1.906 & 1 & 0.167 & 0.332 & 0.069 to 1.589 & \\
\hline & CIRS & 4.953 & 1 & 0.026 & 0.297 & 0.102 to 0.865 & \\
\hline & Gender (male vs female) & 1.474 & 1 & 0.035 & 0.412 & 0.104 to 0.962 & \\
\hline \multirow[t]{3}{*}{ Model } & & $\chi^{2}$ & df & $P$ values & $\begin{array}{l}\text { Pseudo- }{ }^{2} \\
\text { (Cox and } \\
\text { Snell) }\end{array}$ & $\begin{array}{l}\text { Pseudo- }{ }^{2} \\
\text { (Nagelkerke) }\end{array}$ & $\begin{array}{l}\text { Pseudo- }{ }^{2} \\
\text { (McFadden) }\end{array}$ \\
\hline & Likehood ratio test & 17.8 & 9 & 0.044 & 0.221 & 0.314 & 0.221 \\
\hline & Hosmer-Lemeshow test & 1.604 & 4 & 0.708 & - & - & - \\
\hline
\end{tabular}

CIRS, Cumulative Illness Rating Scale.

self-care maintenance. ${ }^{16}$ Conversely, in our study, men seem to exhibit low levels of both self-care management and maintenance, and higher levels of self-care confidence, which is what these patients bring to bear in terms of self-efficacy to overcome their disease. These results are consistent with previous general descriptions of Italian patients. ${ }^{17}$ In recent years, there has been a growing interest in understanding self-care gender differences in chronic diseases, ${ }^{32}$ especially in patients with chronic HF, given evidence indicating that patients' selfcare is improved considerably following the integration of educational strategies into their overall treatment plans. ${ }^{5}$ 
Gender differences, however, are an important issue in self-care, especially given the evidence that gender is often a determinant of self-care. ${ }^{17}$

Consistent with current knowledge, the findings of this study confirm that Italian patients with chronic HF have a high frequency of poor self-care. ${ }^{33}$ These findings, with regard to the self-care of Italian patients with chronic HF, are particularly valuable given the real-world sampling used in this study and the fact that participants had only recently completed their cardiological assessment. In fact, unlike previous self-care studies, all the patients in this study were enrolled close to their primary cardiology visit and not simply during follow-up. In other words, this study paints a realistic picture of patients with chronic HF who have only recently received their clinical assessment and have been prescribed lifestyle adjustment therapies. Moreover, the description of patients' self-care deficits in our study is more disconcerting than in previous studies. ${ }^{17}$ Previous studies have reported self-care behaviours in the range of $14.5 \%-24.4 \%,{ }^{17}$ while the current study describes adequate self-care in the range of $7.6 \%-18.0 \%$. In this scenario, gender differences become readily apparent, starting from the bivariate analysis interpretation-where self-care behaviours and self-care confidence have a significant relationship with gender-towards the LR models analysis.

Several recent studies have undertaken to explore the quality of the patient-caregiver relationship in relation to patients' self-care (ie, mutuality). ${ }^{34}{ }^{35}$ It seems that positive patient-caregiver mutuality is associated with better patient self-care. These mutuality studies shape interdependence model paths and might also explain the paradoxical findings in our study, with patient-caregiver mutuality mediating the relationship between self-care confidence and self-care behaviours. In other words, it is reasonable to speculate that men might have a poorer quality relationship with their caregivers than women, where the males' caregivers play an important role helping their male partners to adhere to their clinical recommendation (eg, sodium-restricted diet). If this hypothesis can be corroborated with empirical evidence, then it is logical to include the caregivers of male patients in any educational interventions. ${ }^{36}$

\section{Strengths and limitations}

This study has a number of limitations and strengths. First, the design was cross-sectional and sampling was not randomised. Moreover, this study was a single centre in Italy. Second, the monocentric sampling used in this study was both a limitation and a strength given that the topic of gender difference is so closely related to the contextual culture; as such, this approach depicts a realistic image of the Northern Italian reality. Another strength of this study is the real-world sampling, which adds value to the realistic sense of the investigation. Moreover, to the best of our knowledge, this was the first study of its kind to describe self-care as a dichotomous outcome, using LR models. This approach simplifies the epidemiological interpretation of self-care characteristics, owing to the likelihood interpretation coming from the adjusted OR of the independent variables of the models. In fact, selfcare characteristics are usually studied using structural equation modelling approaches or path analysis, which are very useful latent multivariate approaches, but are less intuitive from an epidemiological point of view.

\section{CONCLUSION}

Self-care is an important issue in multidisciplinary care management programmes aimed at reducing the risk of HF hospitalisation and mortality. There is strong evidence attesting to the clinical benefits of appropriate levels of self-care, as highlighted in the available guidelines. ${ }^{5}$ Notwithstanding, these interventions are far from foolproof and it is not clear what should constitute best practice with respect to the development of tailored educational intervention to support patients with chronic HF. Nonetheless, more needs to be done to patients with chronic HF successfully adjust to cope with their self-care recommendations, follow-ups and lifestyle adjustments. In this scenario, understanding gender differences in selfcare can help to promote further research, the outcomes of which can correctly guide healthcare providers in the provision of educational interventions targeting the needs of this patient group. Our study helps to establish the foundations for such future investigations and may provide some insights for healthcare providers looking to understand gender differences in patients' presentation of self-care behaviours.

Considering these proposals for future research, it is of paramount importance that some consideration be afforded in relation to the complexity of the management of chronic HF. In fact, no understanding of how gender differences impact patients' self-care can be complete without factoring in the quality of the patient-caregiver relationship, which plays a pivotal role in determining actual patient self-care behaviours. In other words, an individual's confidence in their ability to achieve their clinical recommendations (eg, physical exercise, dietary habits, the recognition of signs and symptoms) may be mediated by their caregiver. As such, it is imperative that this caregiver has an understanding of the recommendations on par with the patient. Future research, however, is needed to corroborate this framework.

The results of this study also highlight an important issue related to the frequency of patients with inadequate self-care. There is an urgent need of more awareness regarding the importance of education during hospitalisation and follow-up. Timely educational interventions may be effective in altering patients' self-care behaviours. To call attention to this important topic and to guide follow-up educational priorities, we recommend the longitudinal screening of patients' self-care behaviours during follow-up visits. This approach can also be useful for assessing the quality of the patient-caregiver relationship, and could help to resolve some of the problems 
underpinning the gender differences described here. Notwithstanding, we suggest that only validated instruments be used to perform these assessments. In conclusion, further cross-cultural exploration of gender differences in the self-care of patients with HF is needed to frame our knowledge in this field.

Acknowledgements We wish to thank all the study participants, patient advisers and the data managers for the support in collecting and record the case form reports.

Contributors FD and RC: conceived the study, supervised the collection and data analysis, and wrote the initial manuscript draft. FP, CA, AM and GC: contributed to data collection and analysis, revising the manuscript critically for important intellectual content. All authors: provided guidance on the analytical approach, contributed to the interpretation of results and drafted and revised the manuscript for critical intellectual content.

Funding This study was funded by local research funds of the IRCCS Policlinico San Donato, a Clinical Research Hospital partially funded by the 'Ricerca corrente' fund of the Italian Ministry of Health.

Competing interests None declared.

\section{Patient consent Obtained.}

Ethics approval This study was approved by the local Institutional Review Board of Policlinico San Donato (822/PSD/2017).

Provenance and peer review Not commissioned; externally peer reviewed.

Data sharing statement We intend to make data freely available in the public domain after publication of major findings. Researchers interested in collaborations should contact the corresponding author (rosario.caruso@unimi.it).

Open access This is an open access article distributed in accordance with the Creative Commons Attribution Non Commercial (CC BY-NC 4.0) license, which permits others to distribute, remix, adapt, build upon this work non-commercially, and license their derivative works on different terms, provided the original work is properly cited, appropriate credit is given, any changes made indicated, and the use is non-commercial. See: http://creativecommons.org/licenses/by-nc/4.0/.

\section{REFERENCES}

1. Maggioni AP, Pietro MA. Epidemiology of heart failure in Europe. Heart Fail Clin 2015;11:625-35.

2. Katsanos S, Bistola V, Parissis JT. Acute heart failure syndromes in the elderly: The european perspective. Heart Fail Clin 2015;11:637-45.

3. Go AS, Mozaffarian D, Roger VL, et al. Executive summary: heart disease and stroke statistics-2014 update: a report from the American Heart Association. Circulation 2014;129:399-410.

4. Mozaffarian D, Benjamin EJ, Go AS, et al. Heart disease and stroke statistics-2015 update: a report from the American Heart Association. Circulation 2015;131:e29-322.

5. Ponikowski P, Voors AA, Anker SD, et al. 2016 ESC Guidelines for the diagnosis and treatment of acute and chronic heart failure: The Task Force for the diagnosis and treatment of acute and chronic heart failure of the European Society of Cardiology (ESC)Developed with the special contribution of the Heart Failure Association (HFA) of the ESC. Eur Heart J 2016;37:2129-200.

6. Ruppar TM, Delgado JM, Temple J. Medication adherence interventions for heart failure patients: A meta-analysis. Eur J Cardiovasc Nurs 2015;14:395-404.

7. Riegel B, Dickson VV, Faulkner KM. The situation-specific theory of heart failure self-care: revised and updated. $J$ Cardiovasc Nurs 2016;31:226-35.

8. Riegel B, Masterson Creber R, Hill J, et al. Effectiveness of motivational interviewing in decreasing hospital readmission in adults with heart failure and multimorbidity. Clin Nurs Res 2016;25:362-77.

9. Vellone E, Fida R, Ghezzi V, et al. Patterns of self-care in adults with heart failure and their associations with sociodemographic and clinical characteristics, quality of life, and hospitalizations: a cluster analysis. J Cardiovasc Nurs 2017;32:180-9.
10. Lee CS, Vellone E, Lyons KS, et al. Patterns and predictors of patien and caregiver engagement in heart failure care: a multi-level dyadic study. Int J Nurs Stud 2015;52:588-97.

11. Dunbar SB, Reilly CM, Gary R, et al. Randomized clinical trial of an integrated self-care intervention for persons with heart failure and diabetes: quality of life and physical functioning outcomes. $J$ Card Fail 2015;21.

12. Buck HG, Dickson VV, Fida R, et al. Predictors of hospitalization and quality of life in heart failure: A model of comorbidity, self-efficacy and self-care. Int J Nurs Stud 2015;52:1714-22.

13. Kato N, Kinugawa K, Nakayama E, et al. Insufficient self-care is an independent risk factor for adverse clinical outcomes in Japanese patients with heart failure. Int Heart J 2013;54:382-9.

14. Smith CE, Piamjariyakul U, Wick JA, et al. Multidisciplinary group clinic appointments: the Self-Management and Care of Heart Failure (SMAC-HF) trial. Circ Heart Fail 2014;7:888-94.

15. Regitz-Zagrosek V. Sex and gender differences in health. science \& society series on sex and science. EMBO Rep 2012;13:596-603.

16. Dickson VV, Worrall-Carter L, Kuhn L, et al. Whose job is it? Gender differences in perceived role in heart failure self-care. J Nurs Healthc Chronic IIIn 2011:3:99-108.

17. Cocchieri A, Riegel B, D'Agostino F, et al. Describing self-care in Italian adults with heart failure and identifying determinants of poor self-care. Eur J Cardiovasc Nurs 2015;14:126-36.

18. Ausili D, Rebora P, Di Mauro S, et al. Clinical and socio-demographic determinants of self-care behaviours in patients with heart failure and diabetes mellitus: A multicentre cross-sectional study. Int $J$ Nurs Stud 2016;63:18-27.

19. Farré $\mathrm{N}$, Vela $\mathrm{E}$, Clèries $\mathrm{M}$, et al. Real world heart failure epidemiology and outcome: A population-based analysis of 88,195 patients. PLoS One 2017;12:e0172745.

20. Miller MD, Paradis CF, Houck PR, et al. Rating chronic medical illness burden in geropsychiatric practice and research: application of the Cumulative IIIness Rating Scale. Psychiatry Res 1992;41:237-48.

21. Centers of Disease Control and Prevention (CDC). Assessing Your Weight: Centers of Disease Control and Prevention (CDC).

22. Riegel B, Carlson B, Moser DK, et al. Psychometric testing of the self-care of heart failure index. J Card Fail 2004;10:350-60.

23. Riegel B, Lee CS, Dickson VV, et al. An update on the self-care of heart failure index. J Cardiovasc Nurs 2009;24:485-97.

24. Vellone E, Riegel B, Cocchieri A, et al. Psychometric testing of the self-care of heart failure index version 6.2. Res Nurs Health 2013;36:500-11.

25. Sun GW, Shook TL, Kay GL. Inappropriate use of bivariable analysis to screen risk factors for use in multivariable analysis. J Clin Epidemiol 1996;49:907-16.

26. Riegel B, Jaarsma T, Strömberg A. A middle-range theory of self-care of chronic illness. ANS Adv Nurs Sci 2012;35:194-204.

27. Vellone E, Pancani L, Greco A, et al. Self-care confidence may be more important than cognition to influence self-care behaviors in adults with heart failure: Testing a mediation model. Int J Nurs Stud 2016;60:191-9.

28. Müller-Tasch T, Löwe B, Lossnitzer N, et al. Anxiety and self-care behaviour in patients with chronic systolic heart failure: A multivariate model. Eur J Cardiovasc Nurs 2018;17:170-7.

29. Holzapfel N, Löwe B, Wild B, et al. Self-care and depression in patients with chronic heart failure. Heart Lung 2009;38:392-7.

30. Riegel B, Moser DK, Anker SD, et al. State of the science: promoting self-care in persons with heart failure: a scientific statement from the American Heart Association. Circulation 2009;120:1141-63.

31. Strömberg A. The crucial role of patient education in heart failure. Eur $J$ Heart Fail 2005;7:363-9.

32. Caruso R, Arrigoni $\mathrm{C}$, Magon A, et al. Health determinants in italian type 2 diabetes Mellitus (T2DM) patients: A critical gender differences analysis. J Res Gend Stud 2017;7:93-108.

33. Dellafiore F, Borella A, Magon A, et al. Descriptive pilot study on self-care and daily living activities in Italian patients with heart failure: What are the criticalities? Ric e Prat 2018;34:6-16.

34. Hooker SA, Schmiege SJ, Trivedi RB, et al. Mutuality and heart failure self-care in patients and their informal caregivers. Eur J Cardiovasc Nurs 2018;17:102-13.

35. Vellone E, Dellafiore F, Chung ML, et al. Mutuality and self-care in heart failure patient and caregiver dyads. Eur $J$ Cardiovasc Nurs 2018;17:1.

36. Vellone E, Paturzo M, D'Agostino F, et al. MOTIVATional intErviewing to improve self-care in Heart Failure patients (MOTIVATE-HF): Study protocol of a three-arm multicenter randomized controlled trial. Contemp Clin Trials 2017;55:34-8. 